\title{
Lysosome-Associated Membrane Glycoprotein 1
}

National Cancer Institute

\section{Source}

National Cancer Institute. Lysosome-Associated Membrane Glycoprotein 1. NCI

Thesaurus. Code C104629.

Lysosome-associated membrane glycoprotein 1 (417 aa, $45 \mathrm{kDa}$ ) is encoded by the human LAMP1 gene. This membrane glycoprotein is involved in selectin-mediated cell adhesion and may be involved in tumor cell metastasis. 